Note: This is a pre-copy-editing, author-produced PDF of an article accepted for publication in Substance Use \& Misuse following peer review. The definitive publisher-authenticated version [Morgan M and Grube JW (1997) Correlates of change in adolescent alcohol consumption in Ireland: Implications for understanding influences and enhancing interventions, Substance Use \& Misuse, 32(5), 609-619] is available online at http://www.informaworld.com/smpp/title $\sim$ content=t713597302

\title{
Correlates of change in adolescent alcohol consumption in Ireland: Implications for understanding influences and enhancing interventions
}

Mark Morgan Ph.D., and Joel W. Grube, Ph.D.

\begin{abstract}
Studies of two similar cohorts of students in Ireland in 1984 and 1992 showed a dramatic increase in the consumption of alcohol, especially in the frequency with which students reported being drunk. A comparison of measures obtained at both times showed that there were major changes with regard to beliefs about consequences of alcohol consumption in a direction favourable to consumption as well as increases in the perceived social support for drinking. However, there were no strong indications that changes in problem behaviour were associated with the observed increases in drinking patterns. These results are supportive of some explanatory models of initiation to substance use and have associated implications for programmes designed to reduce consumption
\end{abstract}

\section{Introduction}

Studies seeking to establish the factors associated with substance use among adolescents have utilized a number of strategies to pinpoint the antecedents of such behaviour. Longitudinal studies now testify to the importance of a variety of factors including parental influences (e.g. Vicary and Lerner, 1985), peer influences (e.g. Kandel, 1980; Morgan and Grub, 1991), as well as expectancies regarding consequences (e.g., Leigh, 1989).

However, explanations of substance use are far from complete (Petraitis et al., 1995). In this context, there may be valuable insights to be gained from new methodologies. Thus, information on changes in patterns of drinking over time (time-series studies) may be especially valuable. For example, if it could be established that changes in attitudinal and belief factors were associated with changes in substance use, it would add a significant dimension to understanding changes in substance use. In turn, such finding would give an important indication as to which approaches are most likely to be effective in designing prevention programs.

The present data are drawn from evidence on research on changing patterns of adolescent drinking in Ireland. Below we first describe the main features of alcohol consumption in Ireland. The methodology of the study is then described, followed by a description of the changes in drinking patterns that occurred over 8 years. Some factors associated with these changes are then described. 


\section{Drinking in Ireland}

The pattern of alcohol consumption in Ireland is characterized by the classic pattern of ambivalence, with a large number of "heavy drinkers" coupled with a significant minority of total abstainers. In terms of average consumption per capita. Ireland is a middle-level consumption country (Conniffe and McCoy, 1993). However, up to one-quarter of the adult population were (at least until recently) total abstainers, while about $6 \%$ were drinking at a level that was considered dangerous in terms of the current medical recommendation (O'Connor and Daly, 1985).

In many respects, alcohol consumption among adolescents follows a pattern that mirrors adult drinking patterns. A study of the consumption by 3,000 Dublin adolescents in 1984 showed that while a significant minority had not tried any alcoholic beverage, a minority also had drunk to the point where they felt drunk (Grube and Morgan, 1986). In general, that study showed that the factors associated with consumption were similar to that found in other countries, especially in relation to parental and peer factors. A similar study involving precisely the same schools and age groups was carried out 8 years later (Morgan and Grube, 1994), with the aim of examining changes in consumption and possible changes in factors associated with such consumption.

\section{Method}

\section{Sample}

For both surveys the sampling frame was the official Department of Education list of postprimary schools in the Greater Dublin area. The schools were initially randomly selected to participate in the 1984 survey and within each school all students from one class level participated in the survey. Details of the sample are presented in Table 1.

Table 1. Samples in 1984 and 1992

\begin{tabular}{lll}
\hline & 1984 & 1998 \\
\hline$N \quad 2,927$ & 1,983 \\
$\mathrm{n}$ of schools & 24 & 22 \\
Gender & $48.5 \%$ female & $49.6 \%$ female \\
Age group & & \\
13 years or less & $17.9 \%$ & $8.9 \%$ \\
14 years & 22.0 & 26.7 \\
15 years & 16.8 & 13.6 \\
16 years & 21.4 & 21.0 \\
17 years or more & 22.0 & 29.7 \\
\hline
\end{tabular}

\section{Survey instruments}

The questionnaires in both surveys were designed to measure a wide range of variables relating to drinking. These included past behaviors, attitudes, normative beliefs, expectancy value beliefs, general deviance, as well as socio-demographic characteristics. Subjects were asked if they had ever had a full drink of any alcoholic beverage (beer, cider, wine, or spirits) and if so, how frequently they had consumed alcohol during the last year (not at all - every day) and how many times during the last 12 months they had enough drink to feel drunk (none - every day). Further questions focused on frequency of drinking and being drunk over the last month.

Another series of items sought information on beliefs about the likelihood that drinking will have particular personal consequences, as well as the evaluation of these consequences. These beliefs were expanded by asking respondents how likely that thought that each of 11 consequences would occur to them if they were to drink (very likely - very unlikely) and then 
to evaluate each of these consequences (like very much - dislike very much). Some of these consequences were negative and indicated potentially harmful consequences of alcohol (e.g., getting a hangover), while others were "positive" in the sense that they referred to partially desirable effects of drinking (e.g., feeling relaxed).

The measures of normative beliefs were concerned with the perceptions of the extent to which relevant others drink themselves and with the extent that they approve/disapprove of respondent's drinking. Specifically, students were asked whether their mother, father, best friend, other good friends, students at my school, and students at other schools would disapprove if the respondent were to have two or three drinks of an alcoholic beverage. They were also asked how often each of these people have drunk over the past 12 months (not at all, one or two times - every day). Problem behaviour was measured by asking about the extent to which students had been involved in various kinds of problem behaviors over the last 12 months, including having lied to a teacher, lied to a parent, damaged other people's property, stolen things from a shop, and stolen money.

\section{Survey Administration}

It was arranged with the participating schools that all pupils would be tested at the same time and in students' regular classroom settings. The testing was carried out by experienced personnel from the Economic and Social Research Institute and normally without the class teachers being present.

The test-retest reliability was found to be between .55 and .83, depending on the substance (Morgan and Grube, 1991). Furthermore, by inclusion of a fictitious substance, it was possible to establish that over-reporting was not a serious problem, since only . $3 \%$ indicated use of this "substance".

\section{Results and Discussion}

Changes in Consumption of Alcohol by Adolescents, 1984-92

Tables 2 and 3 provide the basis on which comparisons were made on changes in drinking over the 8-year period. Information is given in Table 2 on lifetime prevalence for each age group, that is, the percentage who indicated that they had consumed any alcoholic drink in their lives, as well as current drinking of various alcoholic beverages. Table 3 shows a comparison of the prevalence of reporting feeling drunk as well as typical amount consumed (percent having three drinks or more) on a drinking occasion.

Table 2. Comparison of Lifetime and Current Drinking in 1984 and $1992^{a}$

\begin{tabular}{|c|c|c|c|c|c|c|c|c|}
\hline & & & \multicolumn{6}{|c|}{ Current drinking $^{\mathrm{C}}$} \\
\hline & \multicolumn{2}{|c|}{ Lifetime prevalence $^{\mathrm{b}}$} & \multicolumn{3}{|c|}{1984} & \multicolumn{3}{|c|}{1992} \\
\hline Age group & 1984 & 1992 & Beer & Wine & Spirits & Beer & Wine & Spirits \\
\hline 13 years and younger & 45.0 & 58.4 & 14.0 & 14.2 & 8.6 & 16.0 & 13.1 & 13.1 \\
\hline 14 years & 57.9 & 68.9 & 24.2 & 21.3 & 15.0 & 23.8 & 16.3 & 15.5 \\
\hline 15 years & 65.7 & 78.3 & 31.8 & 18.1 & 24.8 & 36.3 & 26.2 & 26.9 \\
\hline 16 years & 73.6 & 80.0 & 43.2 & 27.2 & 29.8 & 40.2 & 23.1 & 33.9 \\
\hline 17 years or older & 79.2 & 92.7 & 50.9 & 29.5 & 37.7 & 60.1 & 27.6 & 47.5 \\
\hline Total & 65.0 & 77.9 & 33.7 & 22.6 & 23.8 & 39.3 & 22.1 & 29.8 \\
\hline
\end{tabular}

a Table entries indicate the percentage prevalence

${ }^{\mathrm{b}}$ Refers to the percentage who had tried an alcoholic drink at any time in their loves

${ }^{c}$ Refers to the number who had tried each type of alcoholic beverage during the previous month

A number of points are striking about the changes over the time under consideration. First, as can be seen in Table 2, there was a major increase in those young people who ever tried alcohol (lifetime prevalence). The number of young people who had never tried a drink by 
age 18 had dwindled from over $20 \%$ to just over $7 \%$. Second, there were substantial increase in the numbers who consume large amounts at any given time (Table 3). This suggests that the increase may be in relation of amounts consumed rather than frequency. Third, the strongest evidence that the change in the pattern of consumption has to do with amount consumed comes from the percentages who indicated they felt drunk. In fact, the comparison indicates a dramatic increase at each level. This increase is even more remarkable when it is taken into account that the 1984 question referred to lifetime prevalence while the 1992 question pertained to the previous 12 months. In other words, the increase in frequency is hardly fully reflected in the comparison as presented.

Table 3. Comparison of Prevalence of Feeling Drunk and Typical Amount Consumed in 1984 and $1992^{a}$

\begin{tabular}{lllll}
\hline & \multicolumn{2}{c}{ Prevalence drunk $^{\mathrm{b}}$} & \multicolumn{2}{c}{ Amount consumed $^{\mathrm{c}}$} \\
\cline { 2 - 5 } Age group & 1984 & 1992 & 1984 & 1984 \\
\hline 13 years and younger & 17.5 & 22.5 & 4.1 & 8.8 \\
14 years & 25.4 & 31.4 & 9.6 & 14.1 \\
15 years & 38.3 & 46.8 & 19.2 & 28.4 \\
16 years & 50.2 & 53.9 & 31.2 & 35.1 \\
17 years or older & 58.0 & 73.1 & 38.4 & 513 \\
Total & 38.7 & 49.8 & 20.5 & 27.7 \\
\hline
\end{tabular}

${ }^{a}$ Table entries indicate the percentage prevalence.

${ }^{\mathrm{b}}$ The 1984 question referred to lifetime, while the 1992 question was based on the last year.

${ }^{\mathrm{c}}$ Percent consuming 3 beers or more on a typical drinking occasion.

This pattern of results suggests that the change in the pattern of youthful drinking is in the direction of the norms and practices that has characterized the drinking of Irish adults, viz., relatively large amounts at any given occasion, and consumption of beer and spirits rather than wine. What is new is the finding that while a significant minority of young Irish people traditionally abstained from alcohol (O'Connor, 1978; Grube and Morgan, 1986), this minority has dwindled substantially.

One possible explanation for the increase in the level of adolescent drinking is that it was a reflection of a greater level of drinking in the population generally. In other words, it might be the case that the per capita consumption of alcohol increased dramatically during this time and that this was reflected in the ages at which young people were beginning to drink and the amount and frequency of consumption. This explanation focuses on alcohol consumption per se rather than changes in youth culture.

The study by Conniffe and McCoy (1992) presents a detailed account of the consumption of alcohol over the last 30 years in Ireland as a whole. Their results indicate that per capita alcohol consumption in Ireland has not changed dramatically over the years in question. Obviously the limitation of this study is that is represents alcohol consumption in the country as a whole rather than the Dublin area. Nevertheless, it might be expected that if there was a major change in Dublin in which over one-third of the population resides, it would be reflected in the national consumption statistics. Since this is not the case, it seems reasonable to conclude that the change reflects consumption in youth.

\section{Changes in Factors Associated with Alcohol Consumption}

As noted above, both these studies obtained information from students about a variety of factors relevant to drinking. These included attitudes, normative beliefs, expectancy value beliefs, and general deviance. Unfortunately, the measurement of some of these items was not similar in both surveys. Thus, it was possible to make comparisons with regard to the following factors in both: 1) Normative influences, 2) Beliefs about consequences, and 3) Problem behaviour. 
Table 4 presents the mean and standard deviation of each of these in 1984 and 1992 together with the significance of the difference of the mean, as well as the mean $d$ (effect size) for each influence. The $d$ statistic is commonly used in meta-analyses since it allows for comparisons of measures with different scales. In line with recommended practice, it was calculated as follows:

$$
\frac{(1992 \text { mean })-(1984 \text { mean })}{\text { Mean SD 1984/1992 }}
$$

A number of points are evident from Table 4. The first of these is that there were significant differences in the predicted direction (more favourable to alcohol use) with respect to 10 of the 12 measures. Second, these changes were quite substantial and average about onethird of a standard deviation taking along measures into account. Third, there are substantial differences between the three domains of influence in the extent to which differences were apparent. The changes in relation to beliefs about consequences are especially strong, while changes in normative influences are moderately strong. On the other hand, the changes with regard to problem behaviour are not especially large and in two cases are in the direction opposite to that predicted.

\begin{tabular}{|c|c|c|c|c|}
\hline Measure & 1984 Mean & 1992 Mean & $t$ & $d$ \\
\hline \multicolumn{5}{|l|}{ Normative influences: } \\
\hline Mother's approval & 1.93 & 2.27 & $9.44^{\star *}$ & .24 \\
\hline Father's approval & 1.97 & 2.33 & $9.47^{\star *}$ & .26 \\
\hline Best friend's approval & 3.87 & 4.27 & $10.53^{\star *}$ & .33 \\
\hline Other friend's approval & 4.10 & 4.50 & $11.42^{* *}$ & .35 \\
\hline \multicolumn{5}{|l|}{ Beliefs about consequences } \\
\hline Harm health & 2.28 & 2.97 & $18.16^{\star \star}$ & .53 \\
\hline Get into trouble & 2.98 & 3.78 & $21.05^{\star *}$ & .60 \\
\hline Become an alcoholic & 3.24 & 3.79 & $14.10^{* *}$ & .41 \\
\hline Feel happy & 3.05 & 2.45 & $16.66^{\star \star}$ & .47 \\
\hline \multicolumn{5}{|l|}{ Problem behaviour } \\
\hline Lying to teachers & 2.89 & 3.05 & $4.32^{\star \star}$ & .13 \\
\hline Lying to parents & 2.77 & 3.13 & $10.59^{* *}$ & .29 \\
\hline Damaged property & 1.64 & 1.55 & N.S. & -- \\
\hline Stolen & 1.94 & 1.83 & N.S. & -- \\
\hline
\end{tabular}

Table 4. Comparison of Measures in 1984 and 1992 Cohorts

\section{Implications and Limitations}

The present results indicate that the substantial increases in the drinking patterns of Dublin adolescents over a decade were quite strongly associated with changes in beliefs about the consequences of such behaviour and a more supportive normative climate. There was little indication, however, that increases in other forms of problem behaviour were associated with this increase in drinking among the younger cohort. There findings have implications, therefore, for theoretical explanations of substance use as well as for approaches in prevention.

As Petraitis et al., (1995) pointed out, beliefs about the consequences of substance use are central to a number of models that attempt to explain such behaviour including the theory of reasoned action (Ajzen and Fisbein, 1980) and the theory of planned behaviour (Ajzen, 1988). Our results indicate that changes in patterns of use are accompanied by changes in beliefs about consequences, thus supporting the view that such cognitions are important proximal factors in drinking.

The present results are especially supportive of the importance of normative influences on substance use, in particular the finding that the increases in alcohol consumption were accompanied by an increase in perception of social approval. The significance of normative 
support is stressed in a number of explanations of substance use including the theory of reasoned action as well as social learning models of substance use (Bandura, 1986).

Our results offer only modest support for explanations of substance use that stress problem behaviour (e.g., Jessor and Jessor, 1977). This explanation stresses that susceptibility to one kind of problem behaviour like underage drinking is associated with other kinds of antisocial behaviour like truancy, stealing and aggressive behaviour. It seems that the increase in drinking in the second cohort was associated with greater involvement in relatively minor antisocial acts (lying), but not with more serious forms of antisocial behaviour (stealing and vandalism). Interestingly, there is evidence from an earlier study based on factor analyses of what are normally identified as problem behaviors that a general deviance factor is only weakly related to substance use (Grube and Morgan, 1989).

The results have implications for programs designed to delay the onset of drinking or reduce consumption among adolescents. It is interesting to note that many schools curricula in Irish secondary schools began to incorporate modules about alcohol consumption during the eighties and early nineties (Morgan et al., 1996). To the extent that these efforts appear not to been sufficient to prevent the major increase in drinking, the present results underline how ineffectual traditional programs may have been, as the review by Moskowitz (1989) suggested. However, the present result offer guidelines as in the kinds of prevention approaches that may be of particular value. For example, given the evidence on the normative changes accompanying the increases in drinking, there may be value in focusing on correcting the misperception regarding such norms that are frequently held by young people (Banse, 1992).

These results, therefore, provide support which complements the findings of cross-sectional and longitudinal studies which have found that beliefs about consequences and normative support are important factors influencing initiation to substance use. The limitations of this work relate to the lack of information on other societal changes that may have occurred in the interval between the two surveys, including reductions in family size, increase in marital break-down, as well as increasing independence of young people. Future research might give attention to such matters and provide a more comprehensive account of adolescent substance use than has been available until now.

\section{Acknowledgements}

This research was funded in part by the United States Institutes of Health through Grant ROIAA08097 from the National Institute on Alcohol Abuse and Alcoholism to J.W.G. Thanks are due to the Economic and Social Research Institute for carrying out both surveys and to Patrician Madden, Meng-Jinn Chen, and Bettina Friese who helped in developing the instruments for this survey. 


\section{References}

Ajzen, L. (1988). Attitude, Personality and Behavior. Homewood, IL: Dorsey Press.

Ajzen, L., and M. Fisbein (1980). Understanding atttudes and Predicting Social Behavior. Eaglewood Cliffs, NJ: Prentice-Hall.

Bandura, A. (1986). Social foundations of Thought and Action. New-York, NY: Prentice-Hall.

Conniffe, D., and McCoy, D. (1992). Alcohol Use in Ireland - The Economic and Social Implications. Dublin: ESRI General Publications.

Grube, J. W., and Morgan, M. (1986). Smoking, Drinking and Other Drug Use among Dublin Post-primary School Pupils. Dublin: ESRI General Publications.

Grube, J. W., and Morgan, M. (1989). The structure of problem behaviours among Irish adolescents. Br. J. addict. 85: 667-675.

Jessor, R., and Jessor, S. L. (1977). Problem Behavior and Psychosocial Development: A Longitudinal Study of Youth. New York, NY: Academic Press.

Hansen, W. B. (1992). School-based substance abuse prevention: a review of the state of the art in the curriculum, 1980-1990. Health Educ. Res. 7; 403-430.

Kandel, D. B. (1980). Drug and drinking behaviour among youth. Annu. Rev. Sociol. 6: 235285.

Leigh, B. C. (1989). In search of the dwarves: Issues of measurement and meaning of alcohol expectancy research. Psychol. Bull. 105: 361-373.

Morgan, M., and Grube, J. W. (1991). Closeness and peer group influence. Br. J. Soc. Psychol. 30: 159-169.

Morgan, M., and Grube, J. W. (1994). Drinking among Dublin Post-primary School Pupils. Dublin: ESRI General Publications.

Morgan, M., Morrow, R., Sheehan, A. M., and Lillis, M. (1996). Prevention of substance misuse: Rationale and effectiveness of the programme, 'On My Own Two Feet'. Oideas: J. Dept. Educ. 44, 3-25.

Moskowitz, J. M. (1989). The primary prevention of alcohol problems: A critical review of the research literature. J. Stud. Alcohol 50: 54-88.

O'Connor, J. (1978). They Young Drinkers: A Cross-National Study of Social and Cultural Influences. London: Tavistock Publications.

O'Connor, J., and Daly, M. (1985). The Smoking Habit. Dublin: Gill and Macmillan.

Petraitis, J., Flay, B. R., and Miller, T. Q. (1995). Reviewing theories of adolescent substance use: Organizing pieces of the puzzle. Psychol. Bull. 117: 67-86.

Boom, R. (1976). Ambivalence as a sociological explanation: The case of cultural explanations of alcohol problems. Am. Sociol. Rev. 20: 155-161.

Thurman, D. (1992). Drinking patterns in Europe. Prof. Statist. 11(8): 2-78.

Vicary, J. R., and Lerner, J. V. (1986). Parental attributes and adolescent drug use. J. Adolesc. 9: 115-152. 